(C) Copyright 2018: Editum. Servicio de Publicaciones de la Universidad de Murcia. Murcia (Spain) ISSN print edition: 0212-9728. ISSN on line edition (http://revistas um es/analesps): 1695-2294. On line edition License Creative Commons 4.0: BY-NC-ND

\title{
Cognitive Switching Affects Arithmetic Strategy Selection: Evidence from Eye-gaze and Behavioral Measures
}

\author{
Xiangyan Wang ${ }^{1}$, Leilei Zhong ${ }^{2}$, Jiwei $\mathrm{Si}^{1 *}$, Weixing Yang ${ }^{1}$, and Yalin Yang ${ }^{1}$ \\ 1 School of Psychology, Shandong Normal University, Jinan (China). \\ 2 Yun Cheng No.1 Middle School, Heze (China).
}

Título: La conmutación cognitiva afecta la selección de estrategia aritmética: Evidencia de patrones de mirada y medidas conductuales.

Resumen: Aunque se han realizado muchos estudios sobre el cambio cognitivo, se sabe poco acerca de si el cambio cognitivo afecta el uso de las estrategias aritméticas por parte de las personas y cómo lo hace. Utilizamos las tareas de estimación y comparación numérica dentro del paradigma de reconocimiento de operandos y el paradigma de elección / no elección para explorar los efectos del cambio cognitivo en el proceso de selección de estrategia aritmética. Los resultados mostraron que el rendimiento de los individuos en la tarea de referencia fue superior al de la tarea de cambio. El modo de presentación y la conmutación cognitiva influyeron claramente en los patrones de la mirada durante la selección de estrategia, con duraciones de fijación más largas en el modo de presentación numérica que en el modo de presentación de reloj. Además, el número de fijaciones fue mayor en la tarea de conmutación que en la tarea de línea de base. Estos resultados indican que los efectos del cambio cognitivo en la selección de la estrategia aritmética están claramente limitados por la forma en que se presentan los números.

Palabras clave: función de conmutación; conmutación cognitiva; selección de estrategia; modo presentación; movimientos oculares.

\section{Introduction}

A strategy can be defined as "a procedure or a set of procedures for achieving a higher level goal or task" (Lemaire \& Reder, 1999). Individuals are capable of using estimation strategies from an early age and can use strategies that are appropriate for different types of problems. Researchers have found two major categories of estimation strategies: the adjusted result strategy (ie. make the estimation results more close to the accurate results) and the digital conversion strategy (transforming the numbers not suitable for mental calculation into a new form which can be easy to calculate) (Chen, Liu, \& Cao, 2009). A study of the estimation of whole-number addition and multiplication has revealed that when solving whole-number problems, college students most frequently used rounding strategy, exact calculation strategy, or supplement strategy (Dowker, 2001).

The primary components of executive function include inhibition function, interference control, working memory, and cognitive switching (Diamond, 2013). As a kind of executive functions, cognitive switching aims to explore the cognitive processes involved in the transition between two or more tasks and are thought to reflect the stability and flexibility of cognitive operations. Many scholars have stud-

* Correspondence address [Dirección para correspondencia]:

Professor Jiwei Si, School of Psychology, Shandong Normal University. Address: No.1, University Road, Science Park, Changqing District, Ji'nan, (P. R. China). Post Code: 250358. E-mail: sijiwei1974@126.com. ORCID: 00000003-1342-7348.
Abstract: Although many studies of cognitive switching have been conducted, little is known about whether and how cognitive switching affects individuals' use of arithmetic strategies. We used estimation and numerical comparison tasks within the operand recognition paradigm and the choice/no-choice paradigm to explore the effects of cognitive switching on the process of arithmetic strategy selection. Results showed that individuals' performance in the baseline task was superior to that in the switching task. Presentation mode and cognitive switching clearly influenced eye-gaze patterns during strategy selection, with longer fixation duration in the number presentation mode than in the clock presentation mode. Furthermore, the number of fixation was greater in the switching task than it was in the baseline task. These results indicate that the effects of cognitive switching on arithmetic strategy selection are clearly constrained by the manner in which numbers are presented.

Keywords: Switching function; Cognitive switching; Strategy selection; Presentation mode; Eye movement.

ied the relationship between switching function and arithmetic strategy use. Chen and Wang (2009) found that executive functions affected the use of arithmetic cognitive strategies in children, the stronger the strategy switching function was, the better the strategy adaptability was. Mao (2012) also found that the reaction time of switching task was higher than repetition task. Moreover, the study of Metcalfe and Campbell (2010) suggested that adults' performance of arithmetic cognitive strategy in mental arithmetic task was influenced by cognitive switching function. Moreover, Bull (2001) found that children with poor inhibitory ability and working memory had difficulty shifting between and choosing strategies for specific tasks. In the eye movement study of executive function, Wang (2011) found that the eye movement indexes produced by participants during the completion of estimation task were related to the scores of central executive component test. Other scholars also pointed out that cognitive switching affected eye movement patterns in strategy execution, and individuals had separation processing of two digit numbers (Moeller, Pinxter, Kaufmann, \& Nark, 2009).

Individuals who have an accurate representation of numbers can use arithmetic strategies in a flexible manner. Although many studies have shown that individuals can represent numbers in the form of a mental number line (Ansari, 2008; Case, Okamoto, Henderson, McKeough, \& Bleiker, 1996; Dehaene, 1997), numerous researchers have experimented with various additional methods of stimulus presentation to explore the characteristics of mental number representation. In the study of Bachtold, Bulmer, and Bragger 
(1998), participants were asked to determine size and time as represented by a ruler and a clock; a standard SNARC (Spatial-Numerical Association of Response Codes) effect was observed in participants who mentally pictured a ruler, whereas a reverse SNARC effect accompanied the clock representation (i.e., the left hand reacted more quickly to large numbers, and the right hand reacted more quickly to small numbers). Wu and You (2007) also found that reaction time and accuracy rate were the best when the rotation angle was between 0 and 45 degrees, and that reaction time increased and accuracy rate decreased when the rotation angle was increased. Studies have also found that clock presentation required individuals to rotate numbers, which made clock presentation occupy more cognitive resources than digital presentation (Burney, 2012). Burney, Valcke and Desoete (2012) pointed out that individuals may use different strategies to conduct transformation with some steps in clock presentation, and more occupation of working memory resources would lead to children with poor mathematical or spatial ability performed worse than normal children.

Both the choice / no-choice method and the operandrecognition paradigm (ORP) are relatively novel paradigms. They are commonly utilized to investigate strategy use. The choice/no-choice method is used to investigate the characteristics of strategy use by assessing the performances related to strategy selection and strategy execution. The use of this method requires two conditions: a choice condition, in which participants can freely choose which strategy they use to solve problems, and a no-choice condition, in which participants must utilize a specified strategy. Additionally, the number of possible strategies under the no-choice condition must be equal to the number of available strategies under the choice condition. Researchers have successfully applied this paradigm to the study of exact addition calculation (Torbeys, Verschaffel, \& Ghesquiere, 2005), spelling (RittleJohnson \& Siegler, 1999), estimation (Lemaire \& Lecacheur, 2002), transformation of currency use (Lemaire \& Lecacheur, 2001), and other tasks. The ORP paradigm uses three successive tasks as part of each trial. At the beginning of each trial, a cue appears on the screen identifying the operation type, and participants then see two operands in succession (task 1), controlling the duration of presentation of each operand. Participants then need to evaluate the answer presented on the screen as either true or false (task 2). The presentation of the "addition" cue requires participants to determine whether the result is the sum of these two operands. The "comparison" cue requires participants to determine whether the result is a number whose value is between these two operands. Upon completion of task 2, a fourth number is presented on one-third of the trials, and participants are required to determine whether the fourth number matches one of the previously seen operands. This paradigm has been applied to studies of double-digit magnitude comparison (Thevenot, Barrouillet, \& Fayol, 2001), addition (Thevenot, Castel, \& Danjon, 2014), and subtraction (Thevenot, Castel, Fanget, \& Fayol, 2010). Researchers have also begun to use the ORP paradigm in research pertaining to strategy use and strategy switching costs. For the purposes of the present study, we omitted the recognition task and transformed the estimation task into a production task while maintaining the essential features of the ORP paradigm.

Although considerable researches on cognitive switching in general have been conducted, we still know very little about how cognitive switching affects arithmetic strategy use. Furthermore, the focus of studies of novel number presentation involving clock presentation has been primarily on the relationship between clock reading and mathematical difficulties. To date, no research has applied clock presentation to the study of arithmetic strategy use. In the current study, we adopted clock presentation and combined this aspect of our experimental design with eye-tracking techniques with the aim of providing a detailed account of how individuals choose strategies in switching tasks compared with in a baseline task.

\section{Methods}

\section{Participants}

Forty-eight college students majoring in psychology (males: 22, females: 26 , mean age $=19.98 \pm 1.38$ ) were randomly selected from a university in Ji'Nan to perform an arithmetic skill test, none of whom had previously participated in similar experiments. All of the 48 participants scored higher than 26 in arithmetic skill discrimination test, and were considered as highly skilled in arithmetic. The experiment was divided into two parts. Half the participants (24 individuals) were randomly selected to perform a digital form of the multiplicative estimation task (ie. Exp. 1), and the remaining half (24) were tested on the clock form of the multiplicative estimation task (ie. Exp. 2). The eyemovement data of 12 (6 in digital form task; 6 in clock form task) participants had to be excluded from further analysis due to inadequate attention to the two multipliers. Each participant in the study received a small gift for participating. An informed consent was obtained prior to participation.

\section{Design and materials}

Three strategy-use conditions (the best-choice strategy, the upward-adjustment strategy, and the downwardadjustment strategy) were designed based on previous research (e.g., Imbo, Duverne, \& Lemaire, 2007). A 2 (cognitive switching: baseline task vs. switching task) $\times 3$ (strategy use: best choice, rounding up, rounding down) $\times 2$ (presentation mode: digital vs. clock) mixed factorial design was adopted for the analysis of mean reaction time and accuracy rate as well as for average fixation duration and average fixation times in visual areas of interest. Cognitive switching and strategy type were between-groups factors, whereas presentation mode was a within-groups factor. In the baseline task, participants were required to estimate the product of two 
operands; while in the switching task, participants' reaction need to base on the clue of comparison or estimation.

\section{Arithmetic skill discrimination test}

The French Kit, an international test of general arithmetic skills, was used to measure individuals' arithmetic fluency and ability to execute strategies quickly and accurately (French, Ekstrom, \& Price, 1963). This test consists of two subtests: a complex addition task and a complex subtraction and multiplication task. Two minutes were assigned for each subtest, in which participants were instructed to respond to 60 questions as quickly and accurately as possible. The total score was the correct number of answers across both tests.

\section{Estimation and comparison tasks}

Estimation task: The selection of task materials was based on materials used in previous research (following Thevenot, Fanget, \& Fayol, 2007, none of the operands contained a 0 (e.g., $30 \times 48$ ) or a 5 (e.g., $35 \times 48$ ) as the units digit) and on the spatial limitations of clock presentation (e.g., mental rotation of the clock was not used, as it would place greater demands on working memory). The clock face was divided in the clockwise direction into 100 segments, with each quadrant containing four double-digits numbers: $17,18,23,24,31,32,48,49,57,58,63,64,76,79,82$, and 83. Forty multiplicative estimation problems were created as follows: four double-digit numbers from each quadrant were used to create within-quadrant mixed problems, and eight double-digit numbers from each quadrant pair were used to create between-quadrant mixed problems; of these, 20 were rounding-up problems, and 20 were rounding-down problems. For half of all problems, the larger multiplier occurred before the smaller one. Similarly, for half the problems, multipliers with the larger unit digit occurred before the multiplier with the smaller unit digit. Identical problems were used in the digital and clock presentation modes.

Comparison task: The materials used in the comparison task were consistent with those used in the estimation task. For example, the previous task might require participants to estimate the multiplication of 17 and 24, in the present task, participants were asked to determine whether 23 represented a numerical value between 17 and 24 . We will refer to the first two numbers (e.g., 17 and 24 above) as the first number and the second number respectively, and we will refer to the number to be judged (e.g., 23) as the third number (third numbers $=$ first number or second number \pm 1 or 2 ). Half of all third numbers corresponded to the first number \pm 1 or 2 , and the other half corresponded to the second number \pm 1 or 2 . Additionally, the correct responses were counterbalanced such that, in 20 of the comparison problems, the third number represented a value between the first two numbers, whereas this was not the case in the remaining 20 problems. To prevent the thinking inertia of participants, additional 10 comparison problems were added into the test.
Throughout the experiment, problems were presented pseudo-randomly (shuffling the presentation order of items, with the restriction that each problem occurred only once) following two general combinational patterns (comparison problems - estimation problem and additional comparison problems / comparison problems - estimation problem).

Each participant completed a total of 240 multiplicative estimation problems and 120 comparison problems. In the present study, participants were asked to complete an estimation task using rounding strategy. Rounding-down strategy was defined as rounding both operands down to the nearest decade, such as multiplying 50 by 80 to estimate 51 $\times 89$. Rounding-up strategy was defined as rounding both operands up to the nearest decade, such as multiplying 60 by 90 to estimate $51 \times 89$.

\section{Apparatus}

Experiment Builder 1.6.1 software developed by SR Research of Canada was used to write programs. All problems were presented on a computer-controlled video screen. Participants were seated at a distance of $70 \mathrm{~cm}$ from the monitor. The EyeLink 1000 eye-tracking system was used to record participants' eye movements.

\section{Experiment 1: Tracking eye movements in the digital presentation task to assess the effects of cognitive switching on arithmetic strate- gy selection}

A brief exercise was conducted before the formal experiment, and participants were instructed to focus their attention. The baseline task involved three experimental conditions (the best-choice strategy, the rounding-up strategy, and the rounding-down strategy), each of which contained its own specific instructions and sequence of events. For example, the best-choice condition had the following structure (as shown in Figure 1): The instruction corresponding to that condition appeared on the screen at the beginning of the task. Participants were then required to gaze at the drift calibration point at the center of the screen after visual tuning. The experimenter subsequently pressed a button to initiate the estimation task. Upon remembering the first and the second multipliers, participants were instructed to press a button. Then, participants reported the strategy they chose once they saw a black box appear on the screen. Finally, they pressed the button again as they verbally reported the estimation result. Under the rounding-up and rounding-down conditions, participants were asked to respond using the strategy required by each of these conditions. There were four practice problems prior to the formal experiment. 


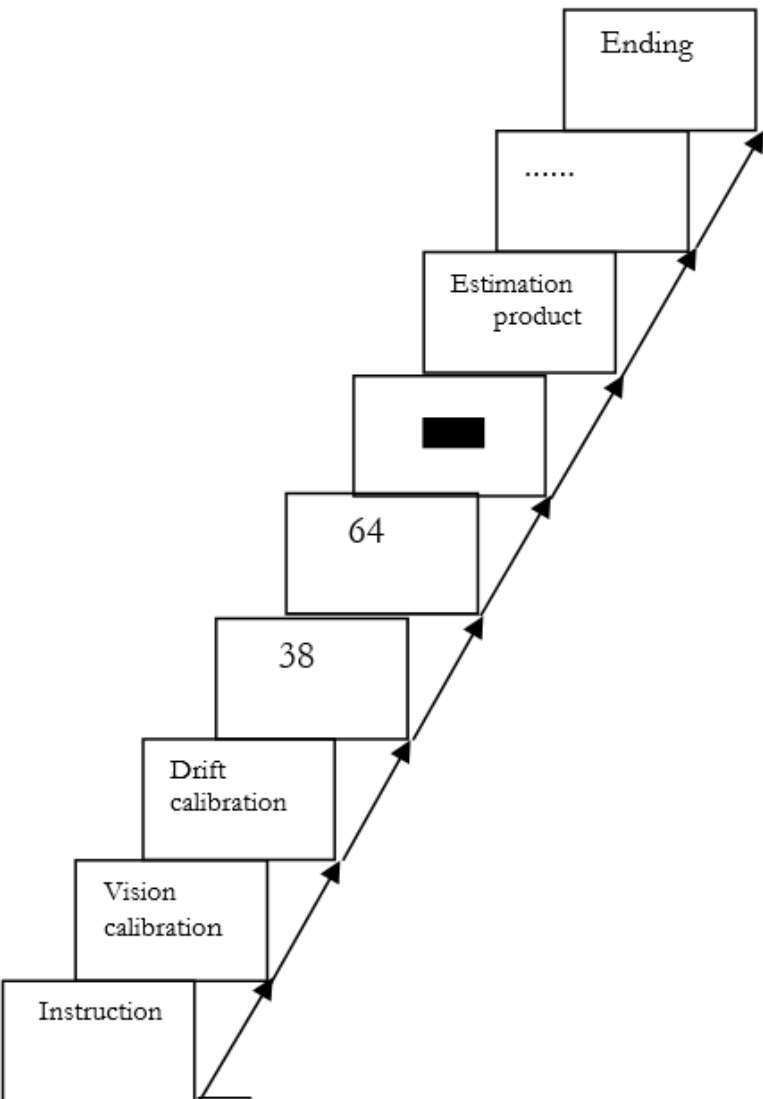

Figure 1. Schematic diagram of the experimental process for the best choice condition of baseline task.

A schematic diagram illustrating the best-choice condition in the digital switching task is shown in Fig 2. Different instructions were presented for each of the experimental conditions to elicit "estimation" or "comparison" responses. The instruction first appeared on the screen, and participants were then required to gaze at the drift calibration point at the center of the screen after visual tuning. Finally, the experimenter pressed the button to initiate the pertinent task. In response to the "estimation" instruction cue, participants were instructed to estimate the product of the two multipliers, report the estimation strategy, and then press the button as they verbally reported the result. In response to the "comparison" cue, participants were required to determine whether the third number represented a value that was intermediate between the first two numbers; they reported "YES" when this was the case and pressed the button to end the trial, and they reported "NO" was this was not the case and pressed the button to end the trial. There were four sets of practice trials prior to the formal experiment.

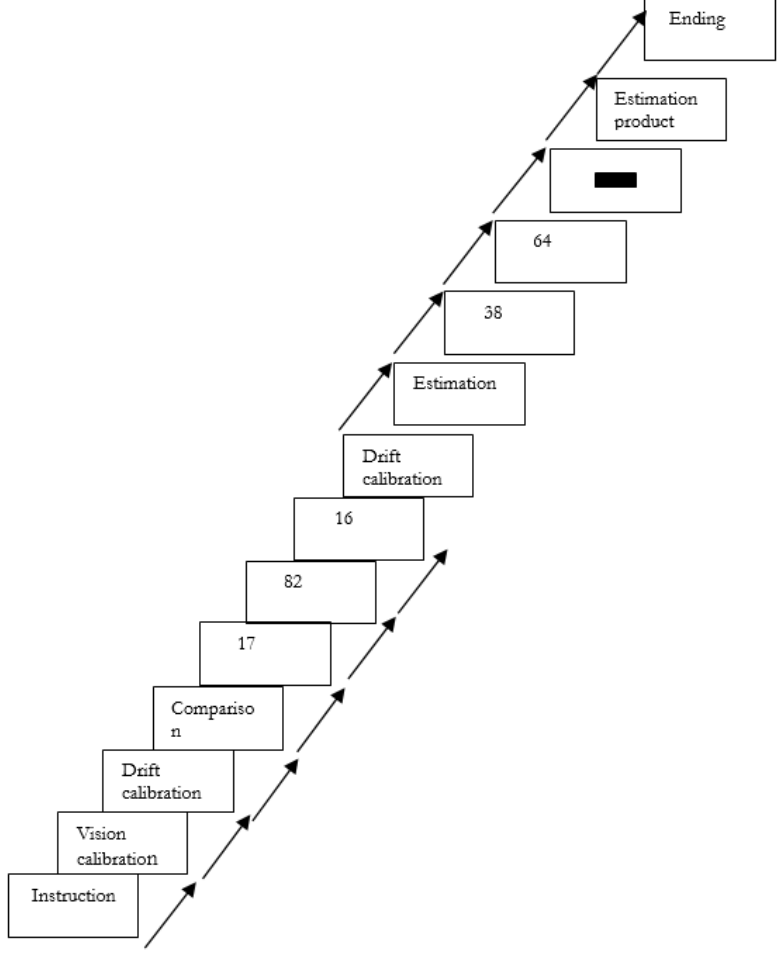

Figure 2. Schematic diagram of the experimental process for the best choice condition of digital switching task.

Experiment 2: Tracking eye movements in the clock presentation task to assess the effects of cognitive switching on arithmetic strategy selection

This experiment implemented the same methods as those described above for Experiment 1, except that the presentation mode was varied. Figure 3 illustrates the manner of presentation for an example trial involving the multipliers 17 and 82 . In the switching task, the third number in the comparison task was presented in the digital mode, whereas the first two numbers were shown using the clock presentation mode.
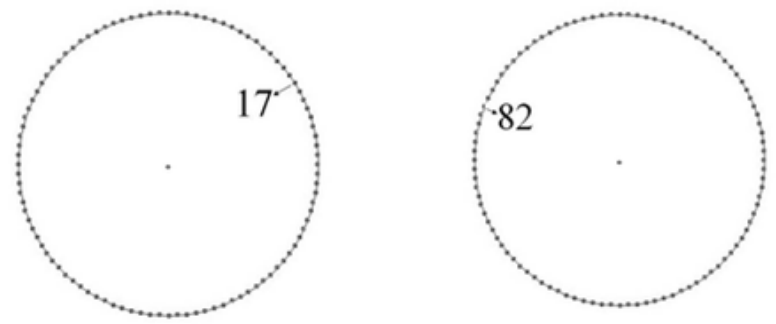

Figure 3. Numbers in clock presentation.

\section{Data analysis}

Data View 1.8.1, SPSS17.0, and Excel 2012 software were used to collect and analyze experimental data. 


\section{Results}

\section{Strategy choice}

Strategy choice was primarily reflected in participants' responses under the best-choice condition. Multipliers were presented individually following the ORP; as participants were required to report the estimation strategy they chose prior to reporting the estimation result, we were able to analyze the relative speed (as reflected in reaction time) and accuracy of each strategy.

\section{Behavioral results}

To explore the patterns of reaction time at different stages of strategy choice, the total reaction time was divided into three stages: $\mathrm{t} 1$ (the reaction time for the first multiplier), $\mathrm{t} 2$ (the reaction time for the second multiplier), and t3 (the reaction time for strategy choice). The results specific to these various stages were shown in Table 1 . A 2 (cognitive switching: baseline vs. switching task) x 2 (presentation mode: digital vs. clock presentation) analysis of variance (ANOVA) was performed on the reaction time obtained for $\mathrm{t} 1, \mathrm{t} 2$ and $\mathrm{t} 3$, respectively.

Table 1. Average reaction time and standard deviation of each stage of strategy choice.

\begin{tabular}{|c|c|c|c|c|}
\hline & & $\begin{array}{l}\text { digital representation } \\
\quad(n=24)\end{array}$ & $\begin{array}{l}\text { clock representation } \\
\qquad(n=24)\end{array}$ & $\begin{array}{c}\text { average RT } \\
(\mathrm{N}=48)\end{array}$ \\
\hline$\overline{\mathrm{BCB}}$ & $\mathrm{t} 1$ & $1887 \pm 636$ & $1950 \pm 751$ & $1918 \pm 689$ \\
\hline $\mathrm{BCB}$ & $\mathrm{t} 2$ & $2899 \pm 1478$ & $3226 \pm 1442$ & $3062 \pm 1454$ \\
\hline $\mathrm{BCB}$ & $\mathrm{t} 3$ & $1706 \pm 641$ & $1478 \pm 640$ & $1592 \pm 659$ \\
\hline BCS & $\mathrm{t} 1$ & $1408 \pm 482$ & $1649 \pm 551$ & $1529 \pm 526$ \\
\hline BCS & $\mathrm{t} 2$ & $2346 \pm 1109$ & $2803 \pm 828$ & $2575 \pm 996$ \\
\hline BCS & $\mathrm{t} 3$ & $1732 \pm 588$ & $1713 \pm 910$ & $1723 \pm 758$ \\
\hline
\end{tabular}

Note: BCB: The best choice of baseline task; BCS: The best choice of switching task.

At the $t 1$ stage, there was no main effect of presentation mode $\left(F_{(1,45)}=1.01, p=.32, \eta^{2}=0.02\right)$ and no interaction between cognitive switching and presentation mode $\left(F_{(1,45)}\right.$ $\left.=1.93, p=.17, \eta^{2}=0.04\right)$, but there was a significant main effect of cognitive switching $\left(F_{(1,45)}=6.35, p=002, \eta^{2}=\right.$ $0.1)$, indicating that the different task types involved in the cognitive switching condition did affect reaction time to the first multiplier. Furthermore, whereas the reaction time for the clock presentation mode was numerically longer than those for digital presentation, there was no significant difference between the two modes $\left(F_{(1,45)}=1.01, p=.32, \eta^{2}=\right.$ 0.02 . Finally, at the t1 stage, reaction time in the best-choice baseline task was significantly longer than those in the bestchoice switching task.

At the $\mathrm{t} 2$ stage, there was no interaction between cognitive switching and presentation mode $\left(F_{(1,45)}=0.21, p=.65\right.$, $\left.\eta^{2}=0.01\right)$, and no main effect of presentation mode was observed $\left(F_{(1,45)}=1.72, p=.20, \eta^{2}=0.04\right)$. However, there was a marginal main effect of cognitive switching $\left(F_{(1,45)}=\right.$ $\left.3.96, p=.06, \eta^{2}=0.01\right)$. Finally, at the 2 stage, reaction time in the best-choice baseline task was longer than those in the best-choice switching task $\left(F_{(1,45)}=11.73, p=0.001, \eta^{2}=\right.$ 0.21).

At the $\mathrm{t} 3$ stage, there was no main effect of cognitive switching $\left(F_{(1,45)}=0.43, p=.52, \eta^{2}=0.01\right)$ or presentation mode $\left(F_{(1,4)}=0.51, p=.48, \eta^{2}=0.01\right)$ and no significant interaction between cognitive switching and presentation mode $\left(F_{(1,4)}=0.93, p=.34, \eta^{2}=0.02\right.$.

Hence, at the $\mathrm{t} 1$ and $\mathrm{t} 2$ stages, reaction time in the bestchoice baseline task was longer than those in the best-choice switching task, whereas no such significant difference occurred at stage $\mathrm{t} 3$ (as shown in Figure 4).

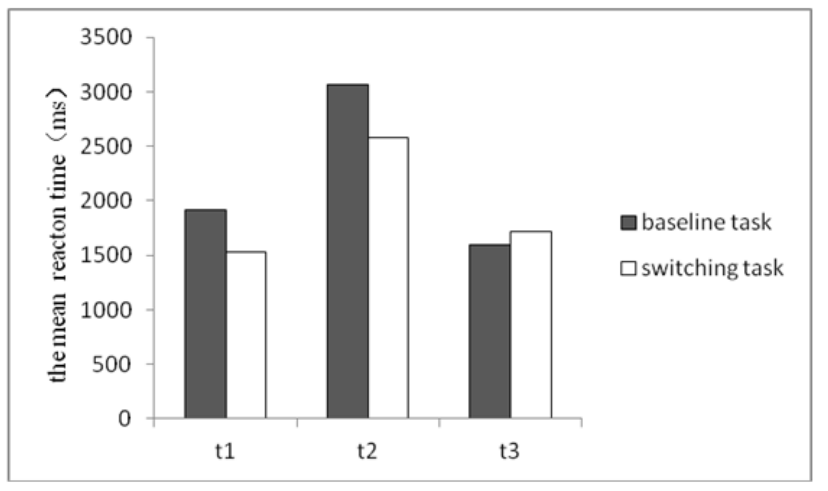

Figure 4. Comparison of the reaction time between $\mathrm{t} 1$, $\mathrm{t} 2$, and $\mathrm{t} 3$ in baseline and switching conditions.

The descriptive statistics pertaining to accuracy rate under the various conditions involving strategy choice are presented in Table 2. A 2 (cognitive switching: baseline vs. switching task) x 2 (presentation mode: digital vs. clock presentation) analysis of variance (ANOVA) was conducted on accuracy rate. We observed no interaction between cognitive switching and presentation mode $\left(F_{(1,45)}=0.60, p=.44\right.$, $\left.\eta^{2}=0.01\right)$, and neither cognitive switching $\left(F_{(1,45)}=0.06, p\right.$ $\left.=.81, \eta^{2}=0.001\right)$ nor presentation mode $\left(F_{(1,45)}=0.60, p=\right.$ $\left..44, \eta^{2}=0.01\right)$ yielded a main effect. Furthermore, although accuracy rate did not differ significantly between the clock and the digital presentation modes $\left(F_{(1,45)}=0.14, p=0.72\right.$, $\left.\eta^{2}=0.003\right)$, the overall accuracy rate of the best-choice switching task (0.583) was almost equal to that of the baseline task (0.58), indicating that there was no difference in the difficulty of these two tasks. 
Table 2. Accuracy rate and standard deviation of the best choice condition of strategy choice.

\begin{tabular}{llll}
\hline & BCB & \\
digital representation $(n=24)$ & $0.58 \pm 0.15$ & BCS \\
clock representation $(n=24)$ & $0.58 \pm 0.17$ & $0.57 \pm 0.16$ \\
average correct rate & $0.58 \pm 0.16$ & $0.60 \pm 0.16$ & $0.58 \pm 0.16$ \\
\hline
\end{tabular}

Note: BCB: The best choice of baseline task; BCS: The best choice of switching task.

\section{Eye movement results}

Using Data View 1.8.1 to manually delineate the visual areas of interest, data of eye movement were recorded in response to the two multipliers under the best-choice condition. Four areas of interest reflecting the issues under investigation was identified: the area corresponding to the tens digit of the first multiplier was coded as "o101" (o: refers to "operand"), the area corresponding to the units digit of first multiplier was coded as "o102", the tens digit of the second multiplier was coded as "o201", and the units digit of the second multiplier was coded as "o202". Differences in fixation duration and fixation times among the four areas of in- terest under the best-choice condition indicate differences in the importance and difficulty of processing each area of interest. In the present study, average fixation duration and average fixation times were the primary measures. Average fixation duration was defined as the average duration of fixations within the area of interest. Average fixation times were the average number of times individuals fixated each area of interest.

Repeated-measure ANOVAs with 2 (cognitive switching: baseline vs. switching task) x 2 (presentation mode: digital vs. clock presentation) factorial designs were conducted on the average fixation duration in the four areas of interest (as shown in Table 3).

Table 3. Average fixation duration and standard deviation of the best choice.

\begin{tabular}{lccc}
\hline & $\begin{array}{c}\text { clock representation } \\
(\mathrm{n}=14)\end{array}$ & $\begin{array}{c}\text { digital representation } \\
(\mathrm{n}=22)\end{array}$ & $\begin{array}{c}\text { average fixation duration } \\
(\mathrm{N}=36)\end{array}$ \\
\hline BCB o101 & $295 \pm 80$ & $352 \pm 116$ & $330 \pm 106$ \\
BCB o102 & $354 \pm 75$ & $373 \pm 110$ & $366 \pm 97$ \\
BCB o201 & $306 \pm 111$ & $402 \pm 140$ & $365 \pm 136$ \\
BCB o202 & $313 \pm 90$ & $444 \pm 205$ & $393 \pm 180$ \\
BCS o101 & $321 \pm 97$ & $361 \pm 81$ & $346 \pm 89$ \\
BCS o102 & $328 \pm 82$ & $377 \pm 102$ & $358 \pm 97$ \\
BCS o201 & $291 \pm 103$ & $396 \pm 110$ & $355 \pm 117$ \\
BCS o202 & $285 \pm 76$ & $417 \pm 153$ & $366 \pm 143$ \\
\hline
\end{tabular}

Note: BCB: The best choice of baseline task; BCS: The best choice of switching task.

Analysis of fixation duration for o101 showed no main effect of cognitive switching $\left(F_{(1,34)}=1.39, p=.25, \eta^{2}=\right.$ $0.04)$ or presentation mode $\left(F_{(1,34)}=2.76, p=.11, \eta^{2}=\right.$ $0.08)$, and no interaction between these two variables $\left(F_{(1,34)}\right.$ $\left.=0.32, p=.32, \eta^{2}=0.01\right)$ was observed. Furthermore, fixation duration did not differ significantly between digital (357 $\mathrm{ms})$ and clock $\left(308 \mathrm{~ms} ; F_{(1,34)}=2.76, p=.11, \eta^{2}=0.08\right)$ presentations or between the switching $(341 \mathrm{~ms})$ and baseline $\left(324 \mathrm{~ms} ; F_{(1,34)}=1.39, p=.25, \eta^{2}=0.04\right)$ tasks.

At the area of interest 0102 , there was no main effect of cognitive switching $\left(F_{(1,34)}=0.64, p=.43, \eta^{2}=0.64\right)$ or presentation mode $\left(F_{(1,34)}=1.27, p=.27, \eta^{2}=0.04\right)$, and there was no interaction between these two variables $\left(F_{(1,34)}\right.$ $\left.=1.22, p=.29, \eta^{2}=0.03\right)$. Furthermore, the fixation duration did not differ between digital $(375 \mathrm{~ms})$ and clock $\left(341 \mathrm{~ms} ; F_{(1,34)}=1.27, p=.27, \eta^{2}=0.04\right)$ presentations or between switching $(353 \mathrm{~ms})$ and baseline $\left(3364 \mathrm{~ms} ; F_{(1,34)}=\right.$ $\left.0.64, p=0.43, \eta^{2}=0.02\right)$ tasks.

At the area of interest 0201 , there was no interaction between cognitive switching and presentation mode $F_{(1,34)}=$ 0.07, $\left.p=.79, \eta^{2}=0.02\right)$, and no main effect of cognitive switching $\left(F_{(1,34)}=0.38, p=.54, \eta^{2}=0.01\right)$ was observed; however, there was a significant effect of presentation mode $\left(F_{(1,34)}=7.39, p=.01, \eta^{2}=0.18\right)$. Moreover, fixation duration did not differ significantly between baseline $(354 \mathrm{~ms})$ and switching $\left(343 \mathrm{~ms} ; F_{(1,3)}=0.38, p=.54, \eta^{2}=0.01\right)$ tasks; however, fixation duration was longer in the digital presentation mode $(399 \mathrm{~ms})$ than in the clock presentation mode $\left(299 \mathrm{~ms} ; F_{(1,34)}=7.39, p=.01, \eta^{2}=0.18\right)$.

At the area of interest o202, there was no interaction between cognitive switching and presentation mode $\left(F_{(1,34)}=\right.$ $\left.0.03, p=.96, \eta^{2}=0.00\right)$, but there was a significant main effect of presentation mode $\left(F_{(1,34)}=6.96, p=.01, \eta^{2}=0.17\right)$. Moreover, there was a significant difference between fixation duration with respect to digital presentation $(431 \mathrm{~ms})$ versus clock presentation $\left(299 \mathrm{~ms} ; F_{(1,34)}=6.96, p=.01, \eta^{2}=0.17\right)$, but fixation duration did not differ significantly between the baseline $(379 \mathrm{~ms})$ and switching $\left(351 \mathrm{~ms} ; F_{(1,34)}=3.82, p=\right.$ $\left..06, \eta^{2}=0.10\right)$ tasks.

Next, we conducted a 2 (cognitive switching: baseline vs. switching task) × 2 (presentation mode: digital vs. clock presentation) analysis of variance (ANOVA) on the average fixation times in the four areas of interest (see Table 4). 
Table 4. Average fixation times and standard deviation of the best choice

\begin{tabular}{|c|c|c|c|}
\hline & $\begin{array}{c}\text { clock representation } \\
(n=14)\end{array}$ & $\begin{array}{l}\text { digital representation } \\
(n=22)\end{array}$ & $\begin{array}{l}\text { average fixation duration } \\
(N=36)\end{array}$ \\
\hline$\overline{\mathrm{BCB}}$ o101 & $1.16 \pm 0.13$ & $1.78 \pm 0.51$ & $1.53 \pm 0,51$ \\
\hline BCB o102 & $1.19 \pm 0.27$ & $2.06 \pm 1.56$ & $1.72 \pm 0.63$ \\
\hline BCB o201 & $1.40 \pm 0.75$ & $1.81 \pm 0.57$ & $1.65 \pm 0.66$ \\
\hline BCB o202 & $1.01 \pm 1.02$ & $2.19 \pm 0.60$ & $1.73 \pm 0.97$ \\
\hline BCS o101 & $1.96 \pm 0.74$ & $1.53 \pm 0.36$ & $1.69 \pm 0.57$ \\
\hline BCS o102 & $1.04 \pm 0.66$ & $3.61 \pm 1.22$ & $3.00 \pm 1.29$ \\
\hline BCS o201 & $1.67 \pm 0.46$ & $1.59 \pm 0.44$ & $1.62 \pm 0.45$ \\
\hline BCS o202 & $1.78 \pm 1.50$ & $1.73 \pm 0.43$ & $1.75 \pm 0.45$ \\
\hline
\end{tabular}

Note: BCB: the best choice of baseline task; BCS: the best choice of switching task

For the area of interest o101, the analysis of the average fixation times revealed a significant interaction between cognitive switching and presentation mode $\left(F_{(1,34)}=32.12, p<\right.$ $\left..001, \eta^{2}=0.49\right)$, indicating that participants fixated on this area more often in the digital presentation mode than in the clock presentation mode when choosing the best strategy in the baseline task $\left(F_{(1,34)}=19.30, p<.01, \eta^{2}=0.36\right)$, whereas they fixated on this area more often in the clock presentation mode than in the digital mode in the best-choice switching task $\left(F_{(1,34)}=5.50, p=.03, \eta^{2}=0.14\right)$. Furthermore, participants showed a greater number of fixation times on this area in the switching task $\left(F_{(1,34)}=30.91, p<.001, \eta^{2}=\right.$ $0.48)$ relative to the baseline task when choosing the best strategy $\left(F_{(1,34)}=4.49, p=.04, \eta^{2}=0.12\right)$.

At the area of interest o102, there was a significant interaction between cognitive switching and representation mode, indicating that more fixation times occurred in the switching task than in the baseline task in both clock and digital presentation modes (clock: $F_{(1,34)}=10.99, p=.02, \eta^{2}$ $=0.24$; digital: $\left.F_{(1,34)}=57.70, p<.001, \eta^{2}=0.63\right)$, Additionally, participants fixated on this region more often in the digital mode than in the clock mode (baseline: $F_{(1,34)}=29.71$, $p<.001, \eta^{2}=0.47$; switching: $F_{(1,34)}=21.171, p<.001, \eta^{2}=$ $0.36)$.

At the area of interest o201, a marginally significant interaction between cognitive switching and presentation mode was observed, indicating that participants fixated on this region more often in the digital presentation task than they did in the baseline task $\left(F_{(1,34)}=3.36, p=.07, \eta^{2}=\right.$ $0.09)$.

At the area of interest o202, we observed an interaction between cognitive switching and presentation mode, indicating that more fixation times occurred in the digital presentation mode than in the clock mode in the baseline task $\left(F_{(1,34)}\right.$ $\left.=18.95, p<.001, \eta^{2}=0.36\right)$. Moreover, we observed that participants fixated this area more often in the switching task when numbers were presented in the clock mode $\left(F_{(1,34)}=\right.$ 12.13, $\left.p=.001, \eta^{2}=2.63\right)$, whereas more fixation times were observed in the baseline task when numbers were presented in the digital mode $\left(F_{(1,34)}=6.67, p=.02, \eta^{2}=0.16\right)$.

\section{Discussion}

The Adaptive Strategy Choice model posits that strategy use consists of two primary components: strategy choice and strategy execution (Siegler \& Shipey, 1995). In this study, we investigated participants' performance on estimation and comparison tasks in two different presentation modes using evidence from eye gaze. Our results showed that individuals performed better in the baseline task relative to the switching task. Patterns of eye movement during strategy choice were influenced by presentation mode and task switching: compared with the clock presentation mode, more fixation times occurred in the digital presentation mode and more fixation times in the switching task than in the baseline task, indicating that the effects of cognitive switching on individuals' choice of arithmetic strategy clearly depended on the number presentation mode.

\section{Influence of cognitive switching on arithmetic strat- egy choice}

By comparing performance in the baseline task (only estimation problems) with that in the cognitive switching task (both comparison and estimation problems), we investigated the effects of central executive function on arithmetic strategy choice. In the switching task, the alternation between comparison and estimation problems involved rule transformation, which, in turn, placed demands on cognitive resources. Differences in performance between the switching and baseline tasks should decrease when conversion resources are adequate.

Data at finer-grained stages indicated that reaction time in the $\mathrm{t} 1$ and $\mathrm{t} 2$ stages was shorter than $\mathrm{t} 3$, but reaction time related to strategy choice in the switching task at the $\mathrm{t} 3$ stage was significantly longer than $\mathrm{t} 1, \mathrm{t} 2$. This is consistent with Mao's (2012) study investigating the influence of cognitive load on task switching. Mao found that participants took more time in task switching than in task repetition, suggesting that cognitive switching places greater demands on cognitive resources; thus, cognitive switching should affect individuals' estimation strategy choices. However, accuracy rate in the baseline task was almost equal to those in the switching task. One explanation for this may be that the problems 
used in this study were relatively easy for participants to solve. However, Bull's (2001) study, which found that children with poor inhibitory ability and working memory had difficulty shifting between and choosing strategies for specific tasks, led us to speculate that this result may be due to problems with the selection of our participants.

In psychological studies involving eye movement, fixation, which refer to periods of time in which the central fossa of the eye is aligned with an object for more than 100 milliseconds for the purpose of detailed visual processing, are taken to be a sign of the importance of that visual object (Zhao, Zuo, \& Ren, 2006). Our analysis of eye-movement data during strategy choice showed that, although cognitive switching did not affect fixation duration within the areas of interest area, it did affect number of fixation times. Simple effect tests revealed that more fixation times occurred in the switching task than in the baseline task, indicating that cognitive switching affected patterns of eye movement during arithmetic strategy choice. This may be due to the presence of comparison trials, in which participants were required to judge the value of the unit digit of a specific number, in the switching task; this may have led to an increase in the number of fixation times to the corresponding area of interest. Based on previous research related to eye-movement patterns and the influence of cognitive switching on strategy execution (Moeller, Pinxter, Kaufmann, \& Nuerk, 2009), we assumed that the processing of the units and tens digits in double-digit numbers reflect separate rather than unitary representation, with individuals eventually integrating representations of units and tens digits.

\section{Influence of digital representation on arithmetic strategy choice}

Bachtfold et al. (1998) found that the speed and accuracy of digital processing depended on the mode of presentation. To further investigate the impact of digital presentation on arithmetic strategy choice, in addition to using a standard Arabic digital presentation, we also used a type of clock presentation, dividing a circle into 100 parts in clockwise order, with segments from 1 to 100 corresponding to numbers rather than to the 60 minutes that constitute an hour.

In our analysis of strategy choice, the total reaction time was defined as the time between the onset of a trial and the end of the participant's strategy selection. After participants reported their choice of strategy, they were required to report their estimation results to confirm that they had correctly understood and applied the roundingup and rounding-down strategies. Certain biases or tendencies in favor of particular strategies may be apparent in data reflecting the cognitive processes underlying the strategy choice during stages as early as at the appearance of the first multiplier. Although we attempted to reduce the effects of such tendencies through normative instruction, these were difficult to completely eliminate. Hence, we used a traditional analysis method to assess total reaction time; our results showed no significant difference between the two presentation modes. Although the analysis suggested an advantage for digital presentation over clock presentation in reaction time at the stage of strategy choice, the difference between the two presentation modes was not significant. Moreover, our analysis of accuracy rate revealed that accuracy was numerically higher in the digital presentation mode, but this difference was, again, not significant. One explanation for the hint of an advantage for digital presentation may be that the clock presentation deviated from the more conventional and familiar digital expression and it therefore consumed greater cognitive resources relative to digital presentation (Burney, 2012). However, according to the Distribution of Associations Model (Siegler \& Shrager, 1984), the strength of the association between problems and their correct answers is related to individuals' exact calculation abilities in completing estimation problems. Individuals found it easier to solve problems when the strength of the association between problems and correct answers was high, showing that actuarial ability plays an important role in this process. Moreover, to choose an appropriate estimation strategy, individuals must make judgments related to the magnitude of the tens and unit digits of the two multipliers, a process is that related to exact calculation ability. Conventional arithmetic skill is less closely related to presentation mode, but individuals with better arithmetic skills tend to be more efficient in choosing a multiplicative estimation strategy. Analysis of our eyemovement data related to the two multipliers revealed, for the most part, longer average fixation duration and more fixation times in the digital presentation mode than in the clock mode. This suggests greater processing of multipliers with digital presentation than with clock presentation, a finding that is inconsistent with previous research (Burney, Valcke, \& Desoete, 2012). Burney et al. (2012) argued that individuals may use various different strategies to perform the multi-steps transformation involved in the clock presentation; this may strain working memory resources, resulting in poorer performance among children with poor mathematical or spatial abilities relative to normal children. There are two possible reasons for the discrepancy between the present study and the previous results. It may be too few participants performed the clock presentation task provide adequate data, resulting in shorter fixation duration and fewer fixation times relative to the digital presentation mode. Additionally, although we selected participants with superior arithmetic skills 
who performed well in arithmetic tests involving digital presentation, we did not control for the variable of arithmetic skill in our analysis of the eye-movement data. Finally, it may be that, because the clock presentation mode involved an unusual presentation of numerical information, it failed to motivate participants to devote their full attention to solving these problems. The results of the study suggest that the more common digital presentation mode may be more effective in eliciting individuals'

\section{References}

Ansari, D. (2008). Effects of development and enculturation on number representation. Nature Reviews Neuroscience, 9(4), 278-291.

Bachtfold, D., Baumuller, M. \& Brugger, P. (1998). Stimulus response compatibility in representational space. Neuropsychologia, 36(8), 731-735.

Bull. R. (2001). Executive functioning as a predictor of children's mathematics ability: Inhibition, switching, and working memory. Developmental Neuropsychology, 19(3), 273-293.

Burny, E. (2012). Time-related competencies in primary education. Doctoral Dissertation. Ghent University: Ghent.

Burny, E., Valcke, M., \& Desoete, A. (2012). Clock reading: An underestimated topic in children with mathematical difficulties. Journal of Learning Disabilities, 45(4), 361-360.

Case, R., Okamoto, Y., Henderson, B., McKeough, A., \& Bleiker, C. (1996). Exploring the macrostructure of children's central conceptual structures in the domains of number and narrative. Monographs of the Society for Research in Child Development, 61(1-2), 59-82.

Chen, L. L., Liu, M., \& Cao, J. M. (2009). Review and prospects of children's estimate strategies (In Chinese). Journal of Mathematics Education, 18(3), 83-86.

Chen, Y. H., \& Wang, M. Y. (2009). Relationship between executive function and arithmetic cognitive strategies in children (In Chinese). Journal of Psychological Science, 32(1), 34-37.

Dehaene, S. (1997). The number sense: How the mind creates mathematics. New York: Oxford University Press.

Diamond, A. (2013). Executive functions. Annual Review of Psychology, 64, $135-168$.

Dowker, A. (2001). Numeracy recovery: A pilot scheme for early intervention with young children with numeracy difficulties. Support for Learning, 16 (1), 6-10.

French, J. W., Ekstrom, R. B., \& Price, I. A. (1963). Kit of reference tests for cognitive factors. Princeton, NJ: Educational Testing Service.

Imbo, I., \& Vandierendonck, A. (2007). The development of strategy use in elementary school children: Working memory and individual differences. Journal of Experimental Child Psychology, 96 (4), 284-309.

Lemaire, P., \& Lecacheur, M. (2001). Older and younger adults' strategy use and execution in currency conversion tasks: Insights from French to Euro and Euro to French Franc conversions. Journal of Experimental Psychology: Applied, 7(3), 195-206.

Lemaire, P., \& Lecacheur, M. (2002). Children's strategies in computational estimation. Journal of Experimental Child Psychology, 82(4), 281-304.

Lemaire, P., \& Reder, L. (1999). What affects strategy selection in arithmetic? An example of parity and five effects on product verification. Memory \& Cognition, 27 (2), 364-382. motivation and interest and that this approach may be advantageous for tasks related to strategy choice.

\section{Conclusion}

In arithmetic strategy selection, presentation mode affects the processing time of operands, and cognitive switching have an influence on eye movement patterns.

Mao, C. X. (2012). The effect of cognitive load on task switching (Unpublished master's thesis). Zhejiang Normal University, Hangzhou.

Metcalfe, A. W. S., \& Campbell, J. I. D. (2010). Switch costs and the operand recognition paradigm. Psychological Research, 74 (5), 491-498.

Moeller, K., Pixner S., Kaufmann L., \& Nuerk H. C. (2009). Children's early mental number line: Logarithmic or decomposed linear? Journal of Experimental Child Psychology, 103(4), 503-515.

Rittle-Johnson, B., \& Siegler, R. S. (1999). Learning to spell: Variability, choice, and change in children's strategy use. Child Development, 70(2), 332-348.

Siegler, R. S., \& Shrager, J. (1984). Strategy choices in addition and subtraction: How do children know what to do? In C. Sophian (Ed.), Origins of cognitive skills (pp.229-293). Hillsdale, NJ: Erlbaum.

Siegler, R. S., \& Shipley, C. (1995). Variation, selection, and cognitive change. In G. Halford \& T. Simon (Eds.), Developing cognitive competence: New approaches to process modeling (pp. 31-76). Hillsdale, NJ: Erlbaum.

Thevenot, C., Barrouillet, P., \& Fayol, M. (2001). Algorithmic solution of arithmetic problems and operands-answer associations in LTM. The Quarterly Journal of Experimental Psychology, 54 A (2), 599-611.

Thevenot, C., Castel, C., Danjon, J., \& Fayol, M. (2014). Identifying strategies in arithmetic with the operand recognition paradigm: A matter of switch cost? Journal of Experimental Psychology: Learning, Memory, and Cognition, 41(2), 541-552.

Thevenot, C., Castel, C., Fanget, M., \& Fayol, M. (2010). Mental subtraction in high- and lower skilled arithmetic problem solvers: Verbal report versus operand-recognition paradigms. Journal of Experimental Psychology: Learning, Memory, and Cognition, 36(5), 1242-1255.

Thevenot, C., Fanget, M.F., \& Fayol, M. (2007). Retrieval or nonretrieval strategies in mental arithmetic? An operand recognition paradigm. Memory \& Cognition, 35(6), 1344-1352.

Torbeyns, J., Verschaffel, L., \& Ghesquiere, P. (2005). Simple addition strategies in a first-grade class with multiple strategy instruction. Cognition and Instruction, 23(1), 1-21.

Wang, Y. X. (2011). Relationship among central executive component, cognitive style and adult arithmetic strategy use: Evidence from estimates (Unpublished master's thesis). Shandong Normal University, Ji Nan.

Wu, Y. W., \& You, X. Q. (2007). Parallel processing mechanism of mental rotation in dual task situations. Acta Psychologica Sinica, 39(5), 785-794.

Zhao, X. C., Zuo, H. F., \& Ren, Y. J. (2006). Review of eye tracker and gaze tracking technology. Computer Engineering and Applications, 12(1), 118-120.

(Article received: 09-07-2017; revised: 05-02-2018; accepted: 19-02-2018) 